\title{
O CONTRIBUTO DA LITERATURA PARA O PROCESSO DE APRENDIZAGEM DA L2: O RECURSO À CRÓNICA DE IMPRENSA
}

\author{
Ângela Filipe Lopes ${ }^{1}$ \\ Maria da Graça L. C. Pinto ${ }^{2}$
}

Resumo: A literatura nem sempre é vista como interveniente óbvia no processo de aprendizagem de uma L2 em virtude de ser considerada como pouco útil ao ensino do uso quotidiano e maioritariamente oralizado das línguas. Este texto propõe um ponto de vista sobre este género textual que implica colocálo no cerne do processo de aprendizagem da L2 pelo contributo que pode trazer ao processo de construção da competência linguística, mas também pela importância que assume no desenvolvimento de uma capacidade metacognitiva que favorece a distância do texto e da situação vivida através dele.

Tendo em mente a relação estreita e complementar da leitura e da escrita, bem como a importância da literatura no contexto letivo em L2, discutem-se intervenções possíveis a partir da crónica literária por se considerar um tipo de texto que, apesar de beneficiar dos traços literários presentes em obras de maior extensão, como o romance ou o conto, os concentra numa peça mais curta e mais flexível.

Palavras-chave: português L2; leitura-escrita; ler em L2; literatura em L2

\begin{abstract}
Literature isn't always seen as a rightful player in a L2 learning process due to the fact that it is regarded as bringing limited value to teaching a language whose use is predominantly seen as a day-to-day oral necessity. We offer a perspective on this text type that entails placing it in the core of the L2 learning process insofar as it may contribute not only to the construction of linguistic competence, but also to the development of metacognitive skills which favor distance from the text and from the situation that the reader experiences by reading the text.

Considering both that reading and writing are closely related in a complementary relationship and that literature is important in a L2 learning environment, we aim at discussing possible takes on reading and writing by using the literary press column. In spite of benefiting from literary traits, this type of text is nevertheless a shorter one when compared to extensive pieces, such as novels or short stories, which means it concentrates the same characteristics while it is more flexible from a teaching perspective.
\end{abstract}

Keywords: L2 Portuguese; reading-writing; L2 reading; L2 literature

\footnotetext{
1 Doutoranda em Ciências das Linguagem - Didática de Línguas.

Universidade do Porto - Faculdade de Letras. Centro de Linguística da Universidade do Porto. angela.tita@gmail.com http:/ / lattes.cnpq.br/7607661461327424

2 Professora Catedrática da Universidade do Porto - Faculdade de Letras mgraca@letras.up.pt http://lattes.cnpq.br/0384767327478026
} 


\section{Introdução}

A leitura e a escrita são uma presença em todos os conteúdos curriculares num processo de aprendizagem de uma língua segunda (L2). Conquanto essa presença seja inegável, podem colocar-se algumas questões relativas aos objetivos que presidem à sua dinamização na aula de L2. Sem prejuízo de outros géneros textuais, até que ponto é o texto literário considerado uma peça essencial na abordagem à leitura e à escrita em L2? Será a literatura relegada para o plano da utilidade enquanto repositório de gramática e de vocabulário? Ou será, em contrapartida, valorizado o seu potencial menos informal e utilitário no processo de apropriação de uma L2?

Estas são questões que se colocam quanto à leitura e à escrita em L2 há muito (HIRVELA, 2001; MATSUDA, 2001), sobretudo por quem as vê como pilares não secundários ou auxiliares, mas principais no desenvolvimento de competências linguísticas gerais (EMIG, 1971; 1977; GRABE 2009; PINTO, 2013a; 2017).

Neste âmbito, há os que defendem o texto literário como uma manifestação da língua na sua plena capacidade de suscitar questionamento, pensamento lógico e aprendizagens múltiplas (BERNHARDT, 2011; GRABE, 2009; HIRVELA, 2001; ROSENBLATT, 1960; SPACK, 1985), motivo pelo qual se considera objeto de leitura profunda, isto é, aquela que exige a mobilização de mais recursos mentais ao serviço da compreensão e da interpretação.

O texto literário é, segundo Todorov (1973), aquele que delega mais trabalho na função do leitor na medida em que "[lhe] incumbe a ele, na verdade, reconstituir a narrativa". (p. 66-67). Ainda nas suas palavras, o leitor vê-se a braços com a tarefa de "revelar o sentido do texto" (p. 8) e de "fazer falar o próprio texto" (p. 8). É interessante que
Todorov (1973) associe as tarefas de compreender e de interpretar textos literários a uma diferença de grau, isto é, quem compreende faz falar o texto, todavia quem o interpreta não se detém na revelação do sentido e questiona-se quanto às "leis gerais que presidem ao aparecimento de cada obra" (p.11) e ao seu funcionamento. A questão prendese com o esforço que esta abordagem à literatura encerra, especialmente numa L2. Que entraves se apresentam ao leitor e que meios poderão estar à sua disposição no sentido de os mitigar?

Assim, seguindo ainda a reflexão sugestiva de Todorov, poderá aferir-se que, quando a descodificação e a compreensão plena do texto não são obstáculo, o leitor passa a apreciar a mecânica do texto como se este fosse um relógio cuja engrenagem estivesse à vista, disponível para análise. Como um observador leigo da alta relojoaria, também o leitor que se encontra neste plano face à leitura pode não saber construir um texto cuja qualidade reconhece, mas tem acesso às peças que o compõem e pode, por isso, valorizá-las e usufruir delas na construção mental do universo que o texto compõe.

Contudo, essa valorização também se materializa frequentemente na apropriação dos recursos que foram lidos anteriormente e na sua reutilização em possíveis momentos de produção escrita própria. $\mathrm{Na}$ verdade, o acesso à mecânica do texto não só auxilia o leitor no processo de compreensão, como também lhe permite reciclar algumas destas peças visíveis em momentos nos quais possa vir a necessitar delas, tanto na escrita como também na oralidade. A apropriação dos elementos da leitura, de que fazem parte instrumentos linguísticos e universos conceptuais, e a sua desejável reutilização na escrita, existe, por vezes, sob a forma de imitação, como refere Eco (2014) (ver também PINTO, 2013b), e, noutros casos ainda, a imitação dá lugar ao ato de originar 
um produto escrito já mais livre de influências iniciais diretas (EMIG, 1977).

De acordo com Emig (1977; 1983), num processo de aprendizagem de leitura e de escrita, esta apropriação pode basear-se na reutilização de algum material linguístico, mas conflui sobretudo na construção geral de uma capacidade de literacia que depende da visão informada da engrenagem do texto e da capacidade transformativa de partir desse ponto para a criação de um produto escrito inteiramente original. Apesar de não se esperar que um estudante de português L2 domine a literatura em português a ponto de ser ele próprio um autor de textos literários, há na concepção de Todorov uma distinção entre compreensão e interpretação que leva a considerar as diversas formas de abordar um texto numa situação de aprendizagem de uma L2 e, neste caso, no contexto do português L2.

Existindo, de facto, uma diferença de patamar nestas duas abordagens à leitura, haverá que considerar as vantagens cognitivas da inclusão mais frequente deste género do processo de aprendizagem, na medida em que, para além do contributo possível da leitura literária para o desenvolvimento da competência linguística geral, talvez não se deva menosprezar uma oportunidade de fomentar cumulativamente uma visão metatextual que poderá elevar a escrita de quem lê. $O$ desenvolvimento da competência escrita, vista como um ponto de relevo no continuum leitura-escrita (HIRVELA, 2004), não se entende como independente da competência leitora (BERNHARDT 2011; HIRVELA, 2001; 2004; PINTO, 2017; STANOVICH, 1986). Se bem que nem todos os textos literários se possam prestar a um tratamento adstrito a limites impostos sobretudo pela duração de unidades letivas ou por exigências curriculares, há no âmbito do texto literário peças que, pela sua extensão, se podem prestar a uma abordagem circunscrita a uma ou duas unidades letivas, como é o caso do conto, do microconto ou da crónica de imprensa de pendor literário.

Este texto abordará a leitura-escrita a partir da leitura literária de extensão curta, como é a crónica. Para tanto, questionam-se as vantagens do tratamento deste tipo de texto a vários níveis que se prendem tanto com o enriquecimento da competência linguística geral em L2, como com o desenvolvimento de capacidades de literacia que passam também pelo reconhecimento da mecânica textual. Por fim, discutem-se possíveis efeitos cognitivos do contacto com o texto literário de uma perspetiva que vê o investimento na reserva cognitiva futura como um imperativo transversal ao ensino das línguas.

Adicionalmente, far-se-ão sugestões relativas a possíveis abordagens deste tipo de texto de um ponto de vista que implica considerar a leitura e a escrita como processos complementares (PINTO, 2013a) na senda da leitura que se considera profunda (BERNHARDT, 1991; 2011).

\section{A leitura profunda}

A diferença a que alude Todorov quando se refere à compreensão e à interpretação leva ao que Bernhardt (2011) vê como o caminho para a leitura profunda e não está longe do que Emig (1983) entende ser uma das principais vantagens de um elevado grau de literacia, aquele que compreende uma visão mais atenta e controlada do texto. Neste patamar de competência, o leitor distancia-se do texto lido num ato de (re)construção do sentido, como também referem Olson (1994) ou Pinto (2014), que passa pela imaginação, mas também pelo conhecimento prévio nos quais se vai apoiando, de acordo com Emig (1983), até atingir "the not-here; the not-now; the not-me" (p. 177). A leitura profunda consiste, então, na compreensão daquilo que,

3 Tradução das autoras: "o não-aqui; o não-agora; o nãoeu" (EMIG, 1983, p. 177) 
dependendo da linguagem verbal, não é explícito e, consequentemente, não é mensurável. Smith (1994) chama-lhe a "deep structure" (p. 26), ou a estrutura profunda, do texto. Esta malha oculta que sustenta o sentido mais preciso do texto sustenta-se na intenção do seu autor e nos meios linguísticos de que se socorre para causar um determinado efeito no leitor que supõe ser aquele que o lê. Desta intenção fazem parte crenças e valores enraizados no contexto histórico e social seu contemporâneo e que naturalmente exercem a sua influência sobre o autor e, indiretamente, sobre o leitor atual e futuro. Por outro lado, este conteúdo é moldado pelos meios linguísticos disponíveis na língua selecionada para o ato da escrita e pela capacidade de trabalhar sobre pensamento e linguagem, de cuja interseção derivam palavras com a carga de sentido pretendida.

Assim, do outro lado do texto, o leitor passa por um processo que oscila entre a descodificação dos elementos de superfície, aqueles que são visíveis, e a reflexão suscitada pelos elementos invisíveis que imagina, numa tentativa de ler para além das linhas que vê (KODA, 2004). Este questionamento dirigido ao texto causa no leitor uma atitude de sucessiva abstração na busca da confirmação de hipóteses que se lhe vão apresentando.

\section{A compreensão abaixo da superfície}

Uma das consequências de ler é a constante verificação do acesso ao sentido que depende do que não é tão óbvio no texto. Contudo, o sentido não é acessível se o leitor enfrentar obstáculos relacionados com a superfície do texto. Estes podem prender-se, por exemplo, com a incapacidade de identificar vocabulário ou de fazer sentido da sua organização oracional ou frásica (BERMAN, 1984; KEMPER \& HERMAN, 2006; KEMPER \& KEMTES, 2002), o que prejudica a compreensão local e, consequentemente, global de uma forma que pode ser determinante. Estes obstáculos possíveis são mais prejudiciais ao acesso e construção do sentido quando a leitura se faz numa L2 (GRABE, 2009; KODA, 2004).

Quando se alude a processos de descodificação, pretende-se chamar a atenção não só para o que subjaz à compreensão mais profunda das diversas camadas do texto, mas para o que permite esse nível de apropriação, isto é, as palavras e a sua organização no suporte em que lemos (papel ou outros). Assim, a leitura bem sucedida tanto depende de processos bottom-up, precisamente aqueles que permitem descodificar os elementos linguísticos de superfície, como daqueles que são top-down, como também dos chamados compensatórios (HIRVELA, 2001; 2004; STANOVICH, 1986; 2000) e que se desenvolvem numa ação interativa ao serviço da compreensão profunda da mensagem escrita (KODA, 2004; 2010; SMITH, 1994; STANOVICH, 1986). Em todo o caso, só quando se leva a cabo uma descodificação fluente, se pode identificar a exigência imposta por camadas mais profundas do texto e refletir sobre o que este exige, mas não mostra à superfície. Nesses casos, como refere Koda (2004), o texto é lido passo a passo, numa tradução sequencial feita de forma mais literal, mas raramente é visto como um todo coerente, isto é, como uma mensagem única, global, comprometendo-se, por isso, o seu sentido.

Não obstante a relação compensatória dos processos que permitem ler, a leitura não é necessariamente um processo sequencial no qual se descodificam e compreendem palavras numa sucessão linear. Pelo contrário, especialmente no caso da leitura em L2, o processo observa avanços e retrocessos numa tentativa constante de aceder ao sentido. Não é raro, portanto, que no decurso da leitura mais complexa ou menos atenta, o leitor tenha de retroceder até um determinado ponto para reavaliar o que leu, mas não compreendeu plenamente. No entender de Grabe e Stoller (2011), ou de Grabe (2009), esta é uma estratégia 
talvez mais frequente e mais consciente entre os leitores de uma L2, embora ocorra também em L1, sobretudo no caso de leituras mais exigentes, mas não só. Quanto mais complexo o trecho lido, maior reflexão exigirá a leitura, levando a ponderar de forma interativa as várias componentes do texto em jogo. Bernhardt (2011) considera que este tipo de leitura se faz sobretudo num registo mais elaborado, como são o literário ou o académico. A leitura destes tipos de texto afigura-se mais complexa e mais sofisticada, ou mais profunda, em virtude de convocar conhecimento prévio mais amplo ou estratégias de compreensão específicas dadas as características do texto a ler, como também refere Hirvela (2001). Isto significa que os recursos mentais mais automáticos ao serviço da compreensão rápida nem sempre são suficientes para dar resposta a temas e configurações verbais menos frequentes.

\section{O texto complexo}

O grau de dificuldade de um texto é dificilmente mensurável, como refere Smith (1994), na medida em que depende do tópico abordado, da linguagem, da construção, bem como de outros fatores que lhe são intrínsecos. Mas estes pontos só se configuram como reflexos de complexidade em face do leitor que se confronta com eles (BERNHARDT 2011; STANOVICH, 1986; PINTO, 2017).

Como refere Koda (2010), a proficiência linguística importa no processo de compreensão leitora, mas não é suficiente. Então, o que pode fazer do texto uma peça difícil de compreender e que leitores podem enfrentar mais obstáculos quando confrontados com um destes textos?

Um texto sobre um tópico desconhecido é uma leitura difícil para um leitor que não o domine, sobretudo se esse texto tiver sido composto tendo em vista um público conhecedor do seu tema e de conceitos implícitos. Em face de uma situação de leitura deste tipo, a descodificação é possível, mas as palavras não se conjugam de forma a originarem sentido na mente do leitor, se a este faltar conhecimento prévio e específico acerca do tema em questão e da linguagem que o descreve. A título de exemplo, identificamo-nos com uma situação de leitura deste tipo se nos propusermos uma leitura técnica acerca de um tópico que não nos é familiar (BRANTMEIER, 2005).

Por outro lado, o tópico pode ser levemente familiar, mas a linguagem na qual o lemos pode apresentar-se mais hermética e fazer uso de termos que não apelam à identificação por parte do leitor, pela sua especificidade ou pela sua sofisticação e ocorrência menos frequente.

Há, assim, dois fatores de peso na relação do leitor com o texto: o grau de familiaridade com o tópico tratado e o grau de proficiência linguística do leitor em L2 (KODA, 2004; GRABE, 2009).

Mas há outros fatores que também pesam no sucesso da compreensão: a motivação para ler, a experiência de leitura e o controlo que o leitor bilingue imprime ao processo. Há, portanto, mais do que apenas uma relação matemática, mecânica, entre o leitor e o texto. Intervêm neste processo constantes julgamentos acerca do conteúdo e sentimentos que este desperta que, por sua vez, apelam à motivação para prosseguir a leitura. De todos estes elementos, nasce um tipo de compreensão de cariz mais inferencial.

Segundo Grabe (2009) e Koda (2004), há dois tipos de processamento inferencial que são essenciais à compreensão profunda por convocarem recursos que vão da descodificação e reconhecimento da mecânica do texto à identificação de pontos que apelam a uma reflexão pessoal enquanto o mesmo texto é questionado. No primeiro caso, os autores referem-se às inferências de ligação ou à identificação de elos entre informações do texto que estão dependentes, 
sobretudo, de mecanismos conjuncionais locais e de relações sintáticas de subordinação. No segundo caso, as inferências prendem-se com a capacidade de elaborar pensamento que já não depende diretamente apenas do texto em questão, mas da experiência do leitor e do propósito da leitura. O primeiro tipo de inferência é automático, mas o segundo é deliberado e depende do controlo que se imprime à leitura (KODA, 2004).

Este segundo tipo de inferência depende das decisões que o leitor toma no sentido de, não só compreender as ideias presentes no texto, mas de as avaliar: até que ponto são centrais ou periféricas? Como se relacionam com outras lidas anteriormente neste e noutros textos? $O$ que podem significar para além do que o texto sugere? E como se relacionam com o próprio leitor?

No âmbito da leitura literária, as inferências mais controladas e a especulação que sugerem levam o leitor a uma liberdade de interpretação que advém dos múltiplos planos de leitura possíveis. No entender de Eco (2014), é esta multiplicidade de leituras que nos coloca em face de ambiguidades que vão para além da linguagem e até da vida como o leitor a conhece, porquanto abrem a porta a questões que nem sempre se lhe colocam. É também desta transcendência de plano que Emig (1983) fala ao referir-se a "the not-here; the not-now; the not-me" (p. 177).

Smith (1994) alude ao significado como o elemento mais profundamente implicado no texto como um todo quando frisa que "meanings do not lie at the surface of language but far more profoundly in the users of language: in the intentions of the speaker or writer and in the interpretations of the listener or reader" (SMITH, 1994, p. 26)

É precisamente porque, como diz Smith (1994), o sentido está para lá das palavras que 4 Tradução das autoras: "os significados não jazem à superfície da língua, mas em planos muito mais profundos, nos utilizadores da língua: nas intenções do falante ou autor e nas interpretações do ouvinte ou do leitor". (SMITH, 1994, p. 26).
Goodman, Goodman e Flores (1979) falam da experiência em diversos quadrantes da leitura quando se referem à biliteracia como fator determinante para a leitura proficiente em L2, corroborando Stanovich (1986) quando este autor se refere ao efeito cumulativo da leitura, sobretudo, no caso das crianças e da L1. De facto, a biliteracia vive não só da transferência possível de conhecimentos que provêm de um saber comum a todas as línguas do falante, o que pode incluir o registo literário, com as devidas diferenças em virtude da cultura que o envolve, mas também da influência intralinguística, como notam Carson et al. (1990). O caráter contínuo da cooperação entre conhecimentos operados sob a influência quer da transferência interlinguística, quer da influência intralinguística resultam num processo psicolinguístico individual (HIRVELA, 2004) que determina um primeiro ataque ao texto e uma atitude que pode favorecer a sua compreensão. Assim, quanto mais o aprendente de uma L2 lê, melhor lerá no futuro e melhor escreverá, tudo leva a crer, por ter ao seu dispor recursos linguísticos que o auxiliarão a atuar sobre o domínio das ideias e da sua verbalização, contanto que a motivação para ler e para escrever persista.

Mas isto também significa que quanto mais experiência tiver o aprendente com leituras variadas, ou mais bagagem (GRABE, 2009), maior será o seu conforto no contacto com fatores inerentes à leitura do texto literário também na L2 que aprende. Por outro lado, os fatores intralinguísticos em jogo não se cingem aos de superfície, mas também abrangem convenções de escrita que podem ser marcadamente culturais tanto na forma como no conteúdo (HIRVELA, 2004).

É na interseção destes fatores, aqueles que são alheios ou prévios à leitura em L2 e aqueles que lhe são intrínsecos, que o papel do docente assume uma importância mediadora essencial ao processo de apreensão das múltiplas camadas do texto, 
especialmente no caso dos aprendentes menos experientes ou menos proficientes como leitores. Contudo, como demonstrou Brantmeier (2005), corroborando a convicção de Berman (1984), optar por estratégias de facilitação do texto não resulta em compreensão melhorada. Pelo contrário, se a opção recair sobre os textos que mais desafiam o leitor em L2, o docente ver-se-á no papel de mediador que descobre as engrenagens do texto e as explica, levando a que estas peças se prestem à reutilização num efeito intralinguístico retroativo.

\section{As vantagens cognitivas da narrativa ficcional}

Entre o público aprendente que aprecia a leitura em português L2, não é difícil encontrar quem veja o texto literário como uma porta para dimensões culturais inerentes à língua que, de outra forma, talvez não se lhe apresentassem. No espectro oposto, quem não aprecia este tipo de leitura defende-se com a sua aparente inutilidade para a vida diária e para a comunicação oral que muitos veem como um patamar mais acessível do ponto de vista do uso útil da língua.

Apesar disso, a leitura ficcional apresenta vantagens linguísticas e culturais, muitas das quais relevantes no contexto letivo (EMIG, 1971, 1983; HIRVELA, 2001; GRABE, 2009; ROSENBLATT, 1960; SPACK, 1985), mas haverá adicionalmente vantagens de cariz cognitivo pelas quais também valha a pena não esquecer a literatura na aula de L2?

$\mathrm{Na}$ verdade, o que parece interessar o leitor de literatura numa primeira abordagem, retomando os patamares de Todorov (1973), é a história. Uma narrativa ficcional apresenta-se-nos como uma história que é vivida à distância. Esse é o objetivo último do texto narrativo: contar uma história a outros. Mas por que razão têm as histórias um impacto tão forte em quem as lê ou em quem as ouve? E que transformações operam no leitor?

Hirvela (2001) fala da busca pelo sentido, numa tentativa de identificação com o conteúdo narrativo que move o aprendente a mobilizar o seu conhecimento prévio. De acordo com o autor, "stories have a universal appeal and cut across all kinds of boundaries in ways that other kinds of texts might not ${ }^{5 "}$ (HIRVELA, 2001, p. 117). Para além disso, Hirvela (2001) refere o seu caráter imaginativo e a sua estrutura narrativa como polos de atração aos quais o público leitor normalmente responde com uma ligação emocional. Esta conexão leva o leitor entusiasta a viver a história em oposição a observar a sua construção ou a informar-se através dela. Daí que a leitura literária leve o seu público ao exercício de empatia com personagens que eventualmente despertem uma variedade de sentimentos pela sua atuação e caracterização (ver também Eco, 2013). Djikic, Oatley e Moldoveanu (2013) aludem mesmo a uma simulação do pensamento em contexto real durante a leitura de ficção. As consequências desta vivência simulada têm vantagens para o estabelecer de uma distância relativamente à leitura e, como explicam os autores, até mesmo no que se refere à visão da realidade:

This double release - of thinking through
events without concern for urgency and
permanence and thinking in ways that are
different than one's own - may produce effects
of opening the mind. ${ }^{6}$ (DJIKIC, OATLEY \&
MOLDOVEANU, 2013, p. 150)

Por outro lado, a curiosidade que desperta uma boa história e a motivação que dela pode derivar podem ser motores de apreciação do texto

5 Tradução das autoras: "as histórias têm um poder de atração universal e transcendem todos os tipos de barreiras de uma forma que pode não estar ao alcance de outros textos" (HIRVELA, 2001, p. 117).

6 Tradução das autoras: "Este duplo escape - pensar à medida que se acompanham os eventos sem a preocupação da urgência e da permanência e pensar em termos que diferem do habitual - pode produzir o efeito de abrir a mente." (DJIKIC; OATLEY; MOLDOVEANU, 2013, p. 150) 
literário a um nível que, a seu tempo, pode ser mais profundo do que aquele que implica a admiração ou a ligação emocional à narrativa ou às suas personagens, numa procura pelos mecanismos que tornam um dado texto numa narrativa excecional (PINKER, 2014). Como diz Spack (1985), "while literature can aid language learning, it must first succeed as literary experience ${ }^{7 "}$ (SPACK, 1985, p. 705).

Há, portanto, uma dimensão pessoal no contacto com o texto literário que dificilmente se verifica em face de uma leitura mais impessoal, mais informativa e menos imaginativa. Rosenblatt (1960) apela à leitura reflexiva a partir da literatura por se configurar como uma oportunidade de especular, em L2, acerca dos meandros do texto e das personagens em causa. Este nível de questionamento vai para além do que o texto ficcional presente em manuais escolares, produzido a pensar em constrangimentos curriculares, implica, porque não contempla objetivos comunicativos quotidianos. Os seus propósitos são outros, mais amplos, e tocam os leitores de formas diferentes. Djikic et al. referem que "[a]lthough nonfiction allows students to learn the subject matter, it may not always belp them in thinking about it8" (DJIKIC; OATLEY; MOLDOVEANU, 2013, p. 153).

Hirvela (2001; 2004) também defende o texto literário na aula de L2 como ponto de partida para a escrita menos espartilhada e para a discussão em grupo. Adianta também que a escrita que parte da leitura literária evoca no leitor o desejo que vai da imitação de estratégias de escrita ao uso mais criativo da linguagem ao serviço da intenção de originar conteúdo inspirado por leituras anteriores. $\mathrm{E}$ assim, os atos de ler e de escrever sustêm-se mutuamente em função das ligações que suscitam

\footnotetext{
7 Tradução das autoras: "mesmo que a literatura possa auxiliar a aprendizagem da língua, deve antes ter sucesso como experiência literária.” (SPACK, 1985, p. 705).

8 Tradução das autoras: "embora a não ficção permita aos estudantes aprender sobre temas, nem sempre os ajuda a pensar sobre os mesmos" (DJIKIC; OATLEY; MOLDOVEANU, 2013, p. 153).
}

e dos pensamentos que originam (ver também EMIG, 1983).

Para os que dizem não gostar de literatura no contexto de aprendizagem de uma L2, o argumento pode ser o de não configurar um ato comunicativo quotidiano, natural ou até necessário. Mas tanto no espectro da leitura, como no seu reverso, o da escrita, a narrativa está presente na vida de qualquer pessoa desde a infância, mesmo nos casos das línguas que não possuem registro escrito, o que nos aproxima a todos da familiaridade de ouvir ou de ler uma história. De facto, a narrativa por si só ajuda a compreender a realidade e a fixá-la no sentido de resistir à erosão do tempo. Não só é, portanto, natural, como necessária.

Ao descrever um paciente com uma perturbação neurológica relacionada com o processamento da visão, Sachs (1985) relata um episódio que demonstra a necessidade da compreensão através da narrativa. No episódio em questão, o neurologista mostrou ao paciente uma imagem do deserto representado apenas por dunas. Este, incapaz de identificar a imagem, descreve-a como se fosse uma cena de uma história. $\mathrm{Na}$ efabulação que a ausência da representação da imagem provocou estariam pessoas sentadas numa esplanada na margem de um rio, junto ao qual haveria diversas cenas de um quadro que em tudo se afastava da representação mental de um deserto. Este episódio demonstra bem a necessidade de criar histórias para fazer sentido da realidade, mesmo quando esta se encontra vedada de alguma forma. Segundo Sachs (1985), este tipo de efabulação constitui uma tentativa de conforto identitário. O que esta reflexão traz é a certeza de que uma construção narrativa fornece, no mínimo, um contexto mais familiar ao aprendente. Contexto esse que acomoda estruturas linguísticas novas ou de menor ocorrência no discurso oral mais quotidiano e que contribuem não só para a 
leitura como processo criativo, como para as suas composições escritas futuras (SPACK, 1985).

\section{A literatura na aula de L2}

O texto literário faz parte dos referenciais do Quadro Europeu Comum de Referência para as Linguas (QECRL, CONSELHO DA EUROPA, 2001) para os níveis de proficiência mais avançados. Em particular, a narrativa ficcional ou a poesia, encontram-se também previstas na abordagem à leitura nestes níveis. Tendo em conta que a leitura de cariz literário pode variar no grau de extensão, pode caber ao docente a seleção de textos que vão ao encontro das circunstâncias letivas em causa.

É frequente associar à leitura literária, a narrativa ficcional de fôlego, como o romance, ou a mais curta, como o conto. Há vantagens em ambas as opções como apontam Grabe (2009), Hirvela (2004), Rosenblatt (1960) e outros. Há, todavia, constrangimentos que se impõem a cursos com uma duração inferior a um semestre ou mesmo a um número de semanas que se preveja ser suficiente para tratar textos mais longos. Nestes casos, há que considerar registros literários mais curtos, mesmo que a tendência seja enveredar por textos de tratamento mais rápido.

Bernhardt (2011) rejeita uma visão muito influenciada pelas abordagens comunicativas anteriores, bem descritas por Matsuda (2001), e chama a atenção para a necessidade de levar o aprendente a um patamar acadêmico do uso da L2 nos níveis mais avançados de proficiência que também passa pela leitura de literatura. A autora registra que

learning to read in the upper registers of a second language entails being able to process the minutiae of word and grammatical nuance while constructing a message and simultaneously remaining aloof from that construction in order to assess its content and intention.9 (BERNHARDT, 2011, p. 19-20)

9 Tradução das autoras: "aprender a ler nos registos mais
A leitura do texto complexo, metafórico, com vocabulário de mais baixa ocorrência quotidiana leva, portanto, à construção de competências de leitura que se caracterizam pela complexidade e pela sensibilidade às variações linguísticas indicadoras de sentido. Afinal, é também um dos objetivos inerentes à aprendizagem de uma L2 ser capaz de exprimir opiniões e emoções com alguma facilidade, embora essa seja uma competência que dificilmente se ensina, como descreve Thompson (2011). Talvez através da literatura, mais exploratória do ponto de vista da caracterização das emoções, seja possível aprender o que, neste campo, nem sempre se explica.

O texto de contornos literários surge tanto como uma fonte de material linguístico, como também cultural, que pode ser útil ao explicar e elaborar pensamento com base em ideias menos concretas e multifacetadas. Para além da vantagem da expressão de pensamento mais pessoal ou matizado, o texto literário fornece uma oportunidade única de contacto não só com uma linguagem mais sofisticada do que aquela que usamos quotidianamente, mas também com uma manifestação cultural de relevo. Assim, a língua é familiar, mas a linguagem é diferente por ser menos literal, por envolver uma resposta menos imediata e dar espaço a interrogações cujas respostas podem ser retardadas ou até inexistentes, retirando ao processo a pressão da tomada de decisões quanto ao conteúdo (DJIKIC et al., 2013). Como afirma Bernhardt (2011), "comprehension has to do with baggage $^{10 "}$ (p. 72), ou com o efeito Mateus, como preconiza Stanovich (1986). A bagagem de cada estudante importa, não só pelo que contribui, mas também e sobretudo pelo que vai ganhando. O tipo

elevados de uma língua segunda implica ser capaz de processar minuciosamente a palavra e a nuance gramatical enquanto se constrói a mensagem e simultaneamente mantendo a distância dessa construção a fim de avaliar o seu conteúdo e a sua intenção." (BERNHARDT, 2011, p. 19-20) (grifos das autoras).

10 Tradução das autoras: "a compreensão tem a ver com a bagagem” (BERNHARDT, 2011, p. 72) 
de estímulo favorecido pela leitura literária favorece sobretudo um papel ativo do leitor, não só na compreensão, mas no reconhecimento da expressão e de emoções comuns veiculadas através de instrumentos verbais mais refletidos, mais variados e mais matizados. A exposição a estas ferramentas leva a que aumentem a probabilidades de serem depois reutilizadas ou recicladas em momentos de escrita ou de produção oral posteriores. Rosenblatt (1960) descreve a relação do leitor com o texto literário de uma perspetiva que justifica uma visão muito ativa da leitura literária:

\begin{abstract}
The reader is thought of as approaching the text like a blank photographic film awaiting exposure. Actually, the reader and the text are more analogous to a pianist and a musical score. But the instrument that the reader plays upon is - himself. His keyboard is the range of his own past experiences with life and literature11 (ROSENBLATT, 1960, p. 304).
\end{abstract}

A autora vê ainda a leitura de um poema ou de um romance como uma porta para experiências linguísticas, como a atenção aos sons, aos ritmos, ao uso das palavras e ao seu sentido, mas também para episódios ou pontos de vista determinados por um certo tempo, por uma certa ordem de eventos e por perspetivas particulares sobre as circunstâncias do momento narrativo.

Por outro lado, o contributo deste género textual é de relevo para a construção de uma base de conhecimento prévio que permita aos aprendentes de português L2 compreender, por exemplo, pistas de comunicação intertextual com as quais se venham a deparar num quadro de leituras variadas. Mas não só, o texto literário contemporâneo ou anterior mostra épocas e costumes intrínsecos à cultura que, de outro modo, dificilmente têm lugar numa aula de L2 de uma forma tão verdadeira.

11 Tradução das autoras: "Pensa-se que o leitor aborda o texto como se fosse uma película fotográfica em branco à espera de ser revelada. $\mathrm{Na}$ verdade, o leitor e o texto estão mais próximos de um pianista e de uma partitura musical. Mas o instrumento que o leitor toca é - ele próprio. O seu teclado é a extensão das suas experiências passadas, na vida e na literatura." (ROSENBLATT, 1960, p. 304).
Grabe (2009) apela precisamente à construção de um banco de conhecimento prévio quando se refere aos dois modelos de compreensão textual preconizados por van Dijk e Kintsch (1983):

The text model calls for understanding what the text itself is trying to signal. The situation model calls for the reader to combine background knowledge with the text information and assists in an effective interpretation of the text in line with the reader's goals12 (GRABE, 2009, p. 46).

Trata-se, assim, também de garantir uma gradual construção de competências variadas que alimentem uma leitura bem sucedida, interativa (BERNHARDT, 1991; STANOVICH, 1986), menos superficial e mais voltada para o que origina o texto e a sua mecânica. No fundo, a interpretação a que alude Grabe (2009) conduz o leitor ao outro lado do texto, o da escrita, aquele que explica determinados mecanismos e objetivos presentes no produto final. É também este tipo de competência que permite que "[i]n the case of literary texts, good readers demonstrate a greater awareness of unusual use of surface-level language structures to convey insights $^{13}$ " (GRABE, 2009, p. 48). Afinal, é este o objetivo último do uso de uma língua: partir da sua mecânica para veicular e compreender o sentido que representa e vice-versa.

\section{A crónica literária}

O texto literário nem sempre parece uma opção flexível ou até exequível no contexto letivo, por vezes, muito constrito por limitações de tempo pouco extensíveis. Assim, e em alternativa ao uso de um texto mais longo, eventualmente dividido

12 Tradução das autoras: "O modelo textual requer uma compreensão do que o próprio texto tenta mostrar. O modelo situacional requer que o leitor combine o conhecimento prévio com a informação do texto e complementa a interpretação efetiva do texto em linha com os objetivos do leitor." (GRABE, 2009, p. 46).

13 Tradução das autoras: "[n]o caso dos textos literários, os bons leitores demonstram uma maior consciência do uso menos comum de estruturas linguísticas de superfície para comunicar perspetivas" (GRABE, 2009, p. 48). 
por várias unidades letivas, talvez a seleção de um ou mais tipos de textos curtos surja como uma alternativa que, sem prejuízo da qualidade literária, aproxime o aprendente deste registo sem que esta seleção implique uma gestão mais difícil do tempo disponível. Tendo em conta a duração de uma unidade letiva ou de uma unidade didática, a crónica pode permitir uma planificação criteriosa e completa de uma aula de leitura e de escrita pelo seu caráter concentrado. Ao mesmo tempo, pode servir de patamar intermédio entre os textos curriculares mais convencionais, objetivos, utilitários e aqueles que se afiguram mais ambíguos, mais pessoais e possivelmente mais complexos.

Não se defende, no entanto, que esta utilização de textos mais curtos, como o microconto, o poema ou a crónica literária, seja vista como uma alternativa à leitura e ao tratamento de textos de fôlego como o romance ou o conto. Pelo contrário, uma abordagem complementar é sempre desejável, sendo só alternativa quando não houver tempo disponível para todos os tipos de leituras.

Valerá a pena então considerar a crónica literária como um material de leitura-escrita que pode potenciar a compreensão leitora e abrir a porta a um género de texto mais desafiante? Que características encerra a crónica literária e por que razões se ajusta aos constrangimentos da aula de português L2 e ao público aprendente adulto?

A variedade de características que são inerentes à crónica literária faz com que seja um tipo de texto versátil, curto e variável no que concerne à linguagem, aos temas e, consequentemente, ao grau de dificuldade que impõe ao leitor de português L2, ou de outras L2s. Por esta razão, configura-se como uma opção interessante no que respeita à exposição ao texto literário profundo e à qualidade que lhe é característica, ao mesmo tempo que permite introduzir um leque amplo de temas e de configurações que trazem variedade à aula de L2. Variar é tanto mais uma necessidade quanto a própria heterogeneidade do público aprendente, sobretudo o adulto que provém de contextos culturais muito diversos. Decorre desta variedade a necessidade de apostar num tipo de texto com camadas de profundidade também diversas pela hibridez que apresenta.

A crónica é descrita por Reis e Lopes (1994) como "um tipo de narrativa de definição algo problemática" (p. 87) que está, na sua génese, preso à temporalidade, mas que a transcende no caso específico da crónica literária. Cruzamse neste tipo de texto aspetos que pertencem ao tempo presente, aos contornos literários que se supõem parte integrante de um currículo de L2 mais avançado, e um tema condensado, de vertente narrativa, ocasionalmente ficcional. A crónica pode considerar-se, por isso, híbrida, de acordo com a conceção de Reis (2018), já que pode ser vista como literária, apresentando, ao mesmo tempo, os traços que se conhecem da crónica de imprensa, colocando-a mais perto do espectro do texto jornalístico.

Por outro lado, é útil pelo facto de atrair, como referem Reis e Lopes (1994), o interesse de "escritores propriamente literários" (p. 89), que lhe conferem uma dimensão narrativa que subsidia contos ou romances ulteriores. Abre-se, assim, a porta ao universo literário em L2 através de textos mais curtos do que o romance ou o conto, mas igualmente multifacetados e ricos. Trata-se, no fundo, de apresentar uma antecâmara da literatura de leitura extensiva sobretudo ao aprendente que não está habituado a este género de texto. Haverá certamente quem, em virtude da sua experiência prévia de leitura e da sua motivação, veja grandes volumes com entusiasmo. Contudo, para outros, a entrada no universo literário em L2 pode representar também o primeiro contacto com o texto literário em geral. Será sobretudo no caso dos mais inexperientes neste registo que a crónica se pode apresentar como um texto que, obedecendo 
às regras literárias, permite um controlo maior por parte do leitor por contar uma história mais curta, que se vê fechada momentos depois de ser aberta. A desmotivação que pode levar a fechar um volume por parecer insuperável não se verifica com uma página apenas, ainda que encerre o mesmo tipo de dificuldades.

Em suma, a crónica literária apresenta como vantagens a sua extensão concisa, a variedade de temas, autores e estilos, sem deixar de exibir também todas as características e benefícios já aludidos quanto ao texto literário como peça fundamental no processo de aprendizagem de uma L2.

Adicionais a estas vantagens, são também as possibilidades de escrita que se abrem a partir da crónica literária que, precisamente por ser um tipo de texto mais sucinto, cuja história se vê fechada em pouco tempo, dá azo a propostas de escrita que beneficiam da proximidade com o texto lido.

De acordo com Emig (1977), a leitura e a escrita em cooperação alimentam o pensamento e a imaginação pela distância do texto e pela invocação de recursos mentais prévios que são geridos a favor do ato de originar conteúdos verbais próprios. Numa descrição do seu próprio percurso como autora, Emig (1983) reflete no seguinte: "initially, what I was able to do was describe; and then after a while what I was able to do was analyse; and last (...) what I was able to do was theorize ${ }^{14 "}$ (p. 145). Como se percebe, há um movimento de afastamento do objeto de leitura e uma gradual transição da descrição do conteúdo lido para uma interpretação. Emig (1983), como Pinto (2017) ou Todorov (1973) aludem a este trânsito, que não é sempre estável e não ocorre sempre sequencialmente, como um dos trunfos da literacia.

14 Tradução das autoras: "inicialmente, o que eu era capaz de fazer era descrever; e algum tempo depois o que era capaz de fazer era analisar; por fim (...) o que era capaz de fazer era teorizar (EMIG, 1983, p. 145).
A questão que advém desta reflexão de Emig (1983) prende-se com o que, do ponto de vista cognitivo, subjaz a uma capacidade ótima de (bi) literacia. Segundo a visão de Stanovich et al. (1996), a resposta reside nas características individuais dos leitores. Neste campo, a variabilidade de experiências com a leitura e com a escrita é tanto mais ampla quanto os interesses decorrentes das múltiplas vivências do aprendente e dos ambientes aos quais foi sendo exposto ao longo da vida. Tendo ainda em atenção que, como frisam os autores, a leitura é uma interface com o ambiente circundante, as atitudes, crenças e hábitos relativos ao registo escrito e ao que ele encerra de cada cultura são também dificilmente quantificáveis. Mas o que Stanovich et al. (1996) salientam é que a exposição frequente ao registo escrito é um preditor da compreensão leitora porquanto fornecem ao leitor "rich bodies of declarative knowledge and large numbers of stored schemata" ${ }^{15 "}$ (STANOVICH et al., 1996, p.17) que por sua vez contribuirão para o enriquecimento da escrita. Esta exposição continuada, talvez mais do que o ensino explícito da escrita, como sublinha Emig (1971), é um fator essencial na construção de capacidades de literacia. Emig $(1971 ; 1983)$ refere que a escrita é mais aprendida do que ensinada numa alusão ao enfoque necessário sobre o aprendente e sobre o que cada um faz do input ao qual é exposto. Diz a autora que "if we meet an enabling environment, one that possesses certain characteristics and presents us with certain opportunities, we will learn ${ }^{16 "}$ (EMIG, 1983, p. 136). Neste processo de aprendizagem individual e irrepetível ainda se destaca a revisão e o seu caráter recursivo, como defendem Murray (2013) ou Pinto (2017), que leva quem escreve a aprender com o

15 Tradução das autoras: "um corpo de conhecimento declarativo rico e um número elevado de esquemas armazenados". (STANOVICH et al., 1996, p.17)

16 Tradução das autoras: "se encontrarmos um ambiente favorável, um que tenha determinadas características e que nos ofereça certas oportunidades, aprenderemos." (EMIG, 1983, p. 136) 
próprio processo de composição continuada, lida, reescrita e relida até ao produto final.

Cabe então, no contexto de aprendizagem do português L2, expor o aprendente ao mais variado número de situações de leitura e de escrita com o intuito de colmatar falhas que advenham da ausência de leituras anteriores e/ ou do desinteresse pela escrita. Por ser um tipo de texto muito variável quanto ao tema, autores e contextos, como o cronológico ou o geográfico, a crónica literária apresenta-se como uma oportunidade de exposição a múltiplas possibilidades tanto no campo da leitura, como no da escrita.

Frequentemente, a escrita é vista como subsequente à leitura, mas essa sequência pode não se verificar. Que benefícios trará olhar para a abordagem à crónica literária como um ponto de partida para a leitura-escrita sem uma cronologia definida para estes dois lados da mesma moeda?

A leitura beneficia da construção de um certo ambiente cognitivo relacionado de alguma maneira com o texto a ler (HIRVELA, 2001). Esta atmosfera gera-se no contacto com outros e alimenta-se de opiniões múltiplas e da mobilização de conhecimento próprio, mas não se esgota nestes pontos. Eles implicam, aliás, a sua fixação e esta requer a intervenção da escrita. Tirar notas, elencar tópicos, relacioná-los e mantê-los próximos faz parte de um processo que não é só de escrita, mas precede a leitura, informando-a e facilitando-a. Spack (1985), ao recomendar esta atitude face à leitura, refere que evita um resumo da história à qual os estudantes de L2 terão acesso ao ler, mas prepara pontos sensíveis, como vocabulário de determinada área que pode não ser familiar ou um contexto histórico presente no texto e potencialmente desconhecido dos leitores em causa. Esta etapa, que a autora diz ser de descoberta, vive da discussão em grupo através do confronto de opiniões, da geração de hipóteses e do registo livre de pontos de interesse que são pessoais, sem que o texto seja de alguma maneira abordado. Mas também pode nascer de outros suportes, como a música, o vídeo ou até outro texto mais curto, como uma citação. A descoberta inicia-se, assim, a partir de um qualquer ponto de contacto que desperte hipóteses na mente do leitor.

É esta fase da leitura-escrita que cria as condições ideais para que durante a leitura propriamente dita as "elaborative inferences" ("inferências elaborativas"), a que Koda (2004) alude, possam intervir de forma decisiva para a compreensão das camadas mais inacessíveis do texto e para a criação de sentido (EMIG, 1977) a partir dum movimento que oscila entre a escrita antes de ler e a escrita depois de ler, porquanto se prepara o terreno para a mobilização de recursos cognitivos para essa etapa, caso venha a existir depois.

Para além deste trabalho especulativo, de elicitação de ideias por via da discussão e do registo de tópicos, não se exclui a possibilidade de pesquisa acerca de qualquer um dos aspetos do texto que o docente possa antecipar como obstáculo à compreensão. Essa pesquisa pode assumir-se como uma tarefa de escrita cujo intuito é também ele exploratório e que deve obedecer aos recursos e às opções de cada um. Num tal tipo de tarefa de escrita antes da leitura de uma determinada crónica, o aprendente pode, por exemplo, optar por pesquisar em qualquer uma das suas línguas acerca do tema proposto, passando a um momento de composição na L2 que aprende (COOK, 2001).

Trata-se, portanto, de contruir redes de sentido também através da escrita antes mesmo de o leitor se confrontar com aquelas que tecem o texto a ler (EMIG 1977; 1983).

Por outro lado, a leitura e a escrita simultâneas também podem assumir-se como estratégias de compreensão do mesmo produto escrito, quer a leitura se destine a informar a escrita, quer seja o 
oposto. A simultaneidade pode ser, neste caso, uma vantagem.

Eco (2013) propõe, para tanto, a introdução do hipertexto como forma de intervenção do leitor sobre o texto que lê. É uma ideia que, num contexto de aprendizagem, pode trazer vantagens, na medida em que permite um ato de apropriação que se pode revelar útil tanto para a compreensão do que o texto pede de pessoal ao leitor, como no domínio da escrita ajustada aos contornos da leitura em questão. Ao mesmo tempo, esta abordagem à escrita sobre o texto em leitura pode conduzir a uma visão menos sacralizada da crónica literária, ou de outro tipo de texto, porquanto convida à sua modificação. Estas alterações podem implicar a desconstrução do texto, a sua reorganização ou a substituição de partes, num ato transformador do leitor sobre o texto, aproximando-se estas modificações da revisão transformadora e recursiva que Murray (2013) e Pinto (2013; 2017) preconizam para a escrita. Ao intervir sobre uma crónica publicada de forma pessoal, mas criteriosa e intencional, o leitor experimenta a escrita num ato de aprendizagem que mobiliza associações de conhecimentos e recursos linguísticos. Talvez não se deva, portanto, olhar o texto literário como um objeto intocável, mas como uma oportunidade de aprendizagem que também se aproveita através da transformação. Por esta via, também se espera que, ao manipular uma crónica como se fosse sua, o leitor se comporte como um mineiro, como sugere Hirvela (2004). Ao minar o texto em busca de momentos nos quais o leitor pode assumir o papel de autor e intervir sobre o texto, talvez a consciência dos instrumentos linguísticos ao seu dispor se apure e dê lugar à sua apropriação. Esta intervenção escrita durante a leitura pode materializar-se ainda na reformulação de frases do texto original, na introdução ou eliminação de parágrafos que dão lugar a outros ou a propostas de histórias alternativas.
Por último, no caso da leitura que precede a escrita, existe uma confluência de múltiplas vozes que contribuem para a construção de uma voz própria, expressa num texto que pode aproximarse de um específico, como ocorre com a síntese, ou resultar de leituras variadas em momentos diferentes, como acontece no caso da escrita académica, entre outros tipos de texto.

No que respeita à prática da escrita depois da leitura no âmbito da aprendizagem de uma L2, há tarefas de composição que, pelas suas características, implicam um olhar mais minucioso tanto sobre o texto lido, como sobre aquele que está em produção.

Entre alguns exemplos de tarefas de escrita a partir da leitura, encontram-se composições sujeitas a títulos de textos lidos anteriormente, exercícios de escrita pessoal como uma página de um diário de viagens a partir de um texto do mesmo tipo ou até uma aventura poética com base na leitura de poesia em L2.

De entre várias possibilidades arquitetadas com base numa leitura específica anterior, talvez a síntese seja a mais comum no contexto de aprendizagem de uma L2. Por implicar a produção com base num texto análogo, ou uma imitação, como referem Eco (2014), Emig (1983) ou Pinto (2013a), a síntese configura-se como uma tarefa que convoca o texto lido de uma forma particular, pelo que implica no campo da compreensão leitora, da interpretação e da capacidade de operacionalização dos recursos advindos da leitura na escrita. No entender de Emig (1977), deste processo fazem parte uma segmentação e análise do texto nas suas partes, bem como uma reorganização destes segmentos numa composição renovada que depende da (re)construção de sentido sem comprometer a estrutura linguística que permite essa reconstrução. Por outro lado, a síntese permite ainda beneficiar do que a mesma autora chama de 
"contagion from model" (EMIG, 1983, p. 111). Mais uma vez, no caso da síntese, a crónica literária é um tipo de texto que, sendo mais curto e amiúde narrativo, se presta mais facilmente a este tipo de tarefa.

Sendo certo que o objetivo de expor o aprendente à literatura em L2 não é o de estimular a escrita dentro do mesmo género, também não se preconiza o contrário. Por esse motivo, um certo contágio a partir da leitura pode potenciar uma atitude mais experimental que leve aquele que escreve a correr mais riscos quando se exprime por escrito, ainda que a produção escrita esteja, no caso da síntese, condicionada pelo conteúdo lido. Encara-se, desta forma, esta tarefa como uma revisão do texto que outro escreveu, como se fosse uma primeira versão do texto em produção, isto é, a síntese.

Há, nas múltiplas manifestações do processo de leitura-escrita, um tipo de recursividade que alimenta o pensamento através da escrita levando-o a patamares de abstração sucessivamente mais complexos, isto é, mais distantes do "aqui" e do "agora" que na sua essência constituem um processo de aprendizagem que não se finda no gradual domínio da L2 em questão.

\section{Conclusão}

$\mathrm{Na}$ verdade, como bem expõe Eco (2013), "[a]s obras literárias convidam-nos à liberdade de interpretação porque nos propõem um discurso a partir dos inúmeros planos de leitura e nos colocam perante as ambiguidades da linguagem e da vida" (ECO, 2013, p. 14). É, por isso mesmo, inevitável que se exponha o aprendente de uma L2 a este tipo de manifestação menos utilitária e mais matizada da língua que quer usar.

17 Tradução das autoras: "contágio a partir do modelo" (EMIG, 1983, p. 111).
Ao vermos a leitura e a escrita literárias como manifestações naturais da língua, o registo escrito abre-se a um uso mais criativo, mais original e provavelmente mais compensador para muitos. Experimentar cenários mentais que são mais distantes da realidade de cada um através da leitura literária não pode senão ajudar a ver com maior distância outras realidades, outras pessoas, outras vidas. Talvez essa vivência imaginada estimule um grau de empatia que ajude noutras áreas da vida, contribuindo para uma expansão de mentalidade a que aludem Djikic et al. (2013). Esse investimento pode ser útil em qualquer fase da vida e talvez contribua para uma visão mais ponderada no processamento da informação. Os autores referemse à construção de uma competência metacognitiva intemporal que resulta da leitura literária:

In ancient Greece, all students, no matter their future profession, had to know Homer by heart. The method may seem outdated, yet one may still wonder how such an immersion in literature may have contributed to the education of philosophers, mathematicians, and writers who, although separated from present time by two-and-a-half millenia, developed minds whose supple and agile turns are still admired.18 (DJIKIC; OATLEY; MOLDOVEANU, 2013, p. 153)

No campo mais específico da $\mathrm{L} 2 \mathrm{em}$ aprendizagem, a apropriação dos recursos do texto lido pode ser uma vantagem. Como sublinha Emig (1971;1983), nem tudo o que se ensina é aprendido, motivo pelo qual vale a pena a exposição a manifestações variadas da língua na esperança de algum grau de contágio que exerça uma influência modeladora em produções escritas presentes ou futuras. Esta apropriação pode ser mais ou menos

18 Tradução das autoras: "Na Grécia antiga, todos os estudantes, independentemente da sua profissão futura, tinham de saber Homero de cor. O método pode parecer ultrapassado, contudo podemos ainda assim interrogarnos acerca da forma como esta imersão na literatura pode ter contribuído para a educação de filósofos, matemáticos e escritores que, embora à distância de dois milénios e meio, desenvolveram mentes cuja flexibilidade e agilidade ainda são admiradas. (DJIKIC; OATLEY; MOLDOVEANU, 2013, p. 153) 
intencional, mas caberá ao docente abrir a porta que permita que ela aconteça.

Hirvela (2004) refere-se ao leitor como um mineiro que deliberadamente procura pedras preciosas ao longo do texto, mas nem todos os leitores talvez abordem um texto com a mesma intenção ou controlo. Não obstante, isso não significa que não sejam contagiados de alguma forma por ele. Trata-se de permitir que o contágio aconteça e de abrir espaço à discussão do texto em todas as suas facetas. É na interpretação que nasce da exposição ao texto e da discussão acerca dele que se movimentam as peças linguísticas que moldam e transmitem o sentido. Não só se considera a intenção do autor e a daquele que já leu o texto, mas também os variados pontos de vista dos pares. Desta interseção há de resultar uma visão pessoal do texto, sublinhados e comentários próprios que, recolhidos numa atitude interventiva e revisiva do texto lido, alimentam a escrita, quer seja anterior, simultânea ou subsequente às leituras feitas.

A crónica literária surge, neste âmbito, como uma resposta prática, atual ou histórica, acessível e variada cuja vantagem de responder às várias modalidades de leitura-escrita em L2 e aos vários leitores parece inegável.

Damásio (2013) afirma que a mente de um leitor o define, na medida em que é construída pelas leituras que faz. Mais especificamente, a leitura contribui ainda para a construção da língua individual. Os processos mentais que a leitura e a escrita estimulam decorrem numa espiral associativa de aprendizagem dependente do controlo consciente regulado por estruturas corticais. As línguas e a sua aprendizagem são, em larga medida, regulados por recursos atencionais exigentes (PARADIS, 2004; BIALYSTOK, 2001) que regulam a capacidade de suprimir o irrelevante. Estes mecanismos, comuns à leitura e à escrita, ganham em acumular funções, isto é, ganham em flexibilidade. Embora os circuitos corticais não sejam exclusivamente responsáveis pela apropriação das línguas, são importantes no que toca ao seu uso criativo e mais intrincado precisamente pelo controlo que implicam estes processos.

Corroborando a afirmação de Damásio (2013) sobre a construção mental do leitor, Alberto Manguel, em entrevista ${ }^{19}$ à Revista E (Expresso, 12/09/2020), define a sua biblioteca pessoal como um retrato do seu cérebro. Este retrato não inclui somente o que foi lido, mas o que está por ler, numa reflexão sobre o que a leitura desperta na intenção de leituras futuras de cada um e, eventualmente, de produção escrita. Tendo em conta que a autobiografia de cada leitor, ou o retrato do seu cérebro, resulta do que já foi lido e redunda na intenção de ler mais e, nalguns casos, de escrever melhor, convém que se abra a porta à construção de uma biblioteca também na L2 em aprendizagem. Talvez uma das portas para a construção de uma biblioteca futura, para aqueles que não tenham já uma, possa ser a crónica literária. Espera-se que o acesso à literatura em L2 de forma mais controlada e segura, através deste tipo de texto e da mediação docente, possa despertar a curiosidade para outros tipos de texto e para uma fruição mais completa da língua em aprendizagem através de um tipo de texto cujo suporte online o torna sempre acessível.

\section{Referências}

BERMAN, R. Syntactic components of the foreign language reading process. In: ALDERSON, J. C. \& URQUHART, A. H. (Eds.). Reading in a foreign language. London; New York: Longman, 1984.

BERNHARDT, E. Reading Development in a second language: theoretical, empirical, and classroom perspectives. New Jersey: Ablex Publishing Corporation, 1991.

19 Disponível em https://leitor.expresso.pt/semanario/ semanario2498-2/html/revista-e/-e/alberto-manguel-estabiblioteca-e-a-minha-imortalidade-partilhada (último acesso a 15/09/2020) 
Understanding Advanced Second Language Reading. New York: Routledge, Taylor and Francis Group, 2011.

BIALYSTOK, E. Bilingualism in development. Language, literacy and cognition. New York: Cambridge University Press, 2001.

BRANTMEIER, C. Effects of reader's knowledge, text type, and test type on L1 and L2 reading comprehension in Spanish. The Modern Language Journal. Vol. 89, 2005, p. 37-53.

CARSON, J.E.; CARRELL, P.L.; SILBERSTEIN, S.; KROLL, B.; KUEHN, P.A. Reading-writing relationships in first and second language. TESOL Quarterly, 24 (2), 1990, p. 245-266.

DAMÁSIO, A. O sentimento de si. Corpo, emoção e consciência. Lisboa: Temas e debates - Círculo de Leitores, 2013.

DJIKIC, M.; OATLEY, K.; MOLDOVEANU, M. C. Opening the closed mind: the effect of exposure to literature on the need for closure. Creativity Research Journal, 25 (2), 2013, p. 149-154.

ECO, U. Sobre literatura. Lisboa: Relógio D’Água Editores, 2014.

EMIG, J. The composing processes of twelfth graders. Urbana, Illinois: National Council of Teachers of English, 1971.

Writing as a mode of learning. College Composition and Communication. Vol. 28(2), 1977, p. 122-128.

The web of meaning. Upper Montclair, N.J.: Boynton/ Cook Publishers, Inc., 1983.

GOODMAN, K.; GOODMAN, Y.; FLORES, B. Reading in the bilingual classroom: literacy and biliteracy. InterAmerica Research Associates Inc., 1979.

GRABE, W. Reading-writing relations: Theoretical perspectives and instructional practices. In: BELCHER, D. \& HIRVELA, A. (Eds.) Linking literacies. Perspectives on L2 reading-writing connections. Michigan: The University of Michigan Press, 2001, p. 15-47.

Reading in a Second Language. Moving from Theory to Practice. Cambridge: Cambridge University Press. 2009.

GRABE, W.; STOLLER, F. L. Teaching and researching reading. London, New York: Routledge, 2011.

HIRVELA, A. Connecting reading and writing through literature. In BELCHER, D.; HIRVELA, A. (Eds.) Linking literacies. Perspectives on L2 reading-writing connections. Michigan: The University of Michigan Press, 2001.

. Connecting reading and writing.

The University of Michigan Press, 2004.

KEMPER, S.; KEMTES. Limitations on Syntactic Processing. In: KEMPER, S. \& K. KLIEGL, R. (Eds.). Constraints on Language: Aging, Grammar, and Memory. New York, Boston, Dordrecht, London, Moscow: Kluwer Academic Publishers, 2002.

KEMPER, S.; HERMAN, R.E. Age differences in memory-load interference effects in syntactic processing. The Journals of Gerontology Series B Psychological Sciences and Social Sciences. Vol. 61(6); 2006, p.327-332.

KODA, K. Reading and language learning: Crosslinguistic constraints on second language reading development. Language Learning. Vol. 57 (1), p. 1-44.

Insights into second language reading. A Cross-linguistic approach. New York: Cambridge University Press, 2010.

MATSUDA, P.K. Reexamining audiolingualism: On the genesis of reading and writing in L2 studies. In Belcher, D.; Hirvela, A. (Eds.). Linking literacies. Perspectives on L2 reading-writing connections. Michigan: The University of Michigan Press, 2001, p. 84-105. 
MURRAY, D. M. The craft of revision. Boston: Wadsworth, 2013.

OLSON, D. R. The world on paper. Cambridge: Cambridge University Press, 1994.

PARADIS M. A Neurolinguistic Theory of Bilingualism. Amsterdam/ Philadelphia: John Benjamins Publishing Company, 2004.

PINKER, S. The sense of style. The thinking person's guide to writing in the 21 st century. UK: Penguin Books, 2014.

PINTO, M. da G. L. C. A leitura e a escrita: um processo conjunto assente numa inevitável cumplicidade. Letras de Hoje. Vol 48 (1), 2013a, p. 116-126.

Simpósio 9: Um bom domínio da leitura e da escrita: dos pressupostos ao seu impacto em termos profissionais e de reserva cognitiva. Porto, 2013b, p. 353-362. Disponível em https://www. google.com $/$ url? sa $=$ t\&rct $=j \& q=\& e s r c=$ s\&source =web\&cd=\&ved=2ahUKEwi4gMr614fsAhWM3 OAKHT7WCu8QFjAAegQIARAB\&url=https $\%$ $3 \mathrm{~A} \% 2 \mathrm{~F} \% 2 \mathrm{Fsigarra}$.up.pt $\% 2 \mathrm{Ffep} \% 2 \mathrm{Fen} \% 2 \mathrm{Fpub}$ geral.show_file\%3Fpi_doc_id\%3D15222\&usg= AOvVaw1C6ttdb3ALDHLbf12o0_0t. Acesso em 20 de novembro de 2020.

A escrita. O papel da universidade na sua otimização. Porto: Faculdade de Letras da Universidade do Porto, 2014.

Da revisão na escrita: uma gestão exigente requerida pela relação entre leitor, autor e texto escrito. Revista Observatório Palmas, 3 (4), 2017 , p. 488-517.

ROSENBLAT'T, L.M. Literature: the reader's role. The English Journal. Vol. 49 (5), 1960, p. 304-316.

SACKS, O. The man who mistook his wife for a hat and other clinical tales. New York: Summit Books, 1985.

SMITH, F. Understanding reading. A Psycholinguistic analysis of reading and learning to read. New Jersey: Lawrence Erlbaum Associates,
Inc. Publishers, 1994.

SPACK, R. Literature, reading, writing, and ESL. Bridging the gaps. TESOL Quarterly. Vol. 19 (4), 1985, p. 703-725.

STANOVICH, K. E. Matthew effect in reading. Some consequences of individual differences in the acquisition of literacy. Research Quarterly. Vol. 21 (4), 1986, p. 360-407.

Progress in understanding reading: scientific foundations and new frontiers. New York: The Guilford Press, 2000.

STANOVICH, K. E., WEST, R. F., CUNNINGHAM, A. E., CIPIELEWSKI, J.; SIDDIQUI, S. The role of inadequate print exposure as a determinant of reading comprehension problems. In: C. CORNOLDI; J. OAKHILL (Eds.). Reading comprehension difficulties: Processes and intervention. Mahwah, NJ: Lawrence Erlbaum Associates Publishers, 1996.

THOMPSON, C. Losing my voice and finding another. Learning a second language. Hollister, CA: MSI Press, LLC., 2011.

TODOROV, T. Poética. Lisboa: Editora Teorema. 1973.

VAN DIJK, T.; KINTSCH, W. Strategies of discourse comprehension. New York: Academic Press, 1983.

Submissão: setembro de 2020 . Aceite: novembro de 2020. 